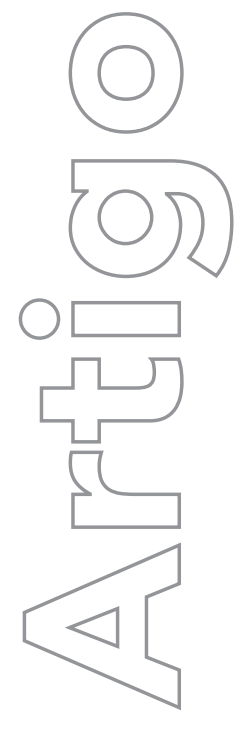

\section{revista}

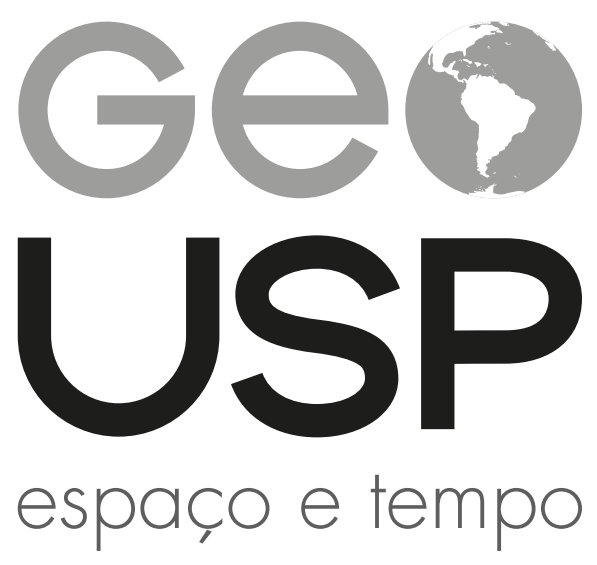

Volume $23 \cdot n^{\circ} 3$ (2019)

ISSN 2179-0892

\section{Políticas de conservação ambiental no Brasil e mercadificação da natureza}

\author{
Carina Inserra Bernini \\ Universidade do Estado de Santa Catarina. \\ Faculdade de Educação e Ciências Humanas
}

p. $662-681$

Como citar este artigo:

BERNINI, C. I. Políticas de conservação ambiental no Brasil e mercadificação da natureza. Geousp - Espaço e Tempo (Online), v. 23, n. 3, p. 662-681, dez. 2019, ISSN 2179-0892.

Disponível em: https://www.revistas.usp.br/geousp/article/view/146059. doi: https://doi.org/10.11606/issn.2179-0892.geousp.2019.146059.

\section{(c) $(1)(9)$}

Este artigo está licenciado sob a Creative Commons Attribution 4.0 Licence 


\title{
Políticas de conservação ambiental no Brasil e mercadificação da natureza
}

\section{Resumo}

Este artigo discute a trajetória das políticas de conservação ambiental no Brasil analisando-as como integrantes do processo de expansão das relações capitalistas de produção. Entendendo que a apropriação e o uso da natureza precisam ser analisados a partir da compreensão das relações sociais que caracterizam a sociedade capitalista, assumimos o conceito de produção da natureza como central nesta análise, considerando que a forma como os processos biofísicos se apresentam em cada lugar resulta da interferência dessa sociedade. E que, ainda que a natureza tenha, em certo nível, um funcionamento independente do homem, 'o conhecimento desse funcionamento é aplicado pela sociedade para fins socialmente definidos. A análise do estabelecimento de unidades de conservação no território brasileiro revela uma estreita relação entre a expansão da fronteira agrícola e o isolamento de áreas destinadas à conservação. Além disso, a gestão dessas áreas tende a inseri-las como redutos da chamada Economia Verde, delimitando produtos que têm a própria natureza "natural" como matéria-prima.

Palavras-chave: Natureza. Estado. Unidades de conservação. Populações tradicionais. Propriedade privada.

\section{Environmental conservation policies in Brazil and the commodification of nature}

\begin{abstract}
This article discusses the history of environmental conservation policies by analyzing such policies as integral to the expansion of capitalist relations of production process. Comprising the appropriation and use of nature need to be analyzed from the understanding of social relations that characterize capitalist
\end{abstract}

A noção de homem é tomada aqui na perspectiva de que, seja como indivíduo ou como espécie, os seres humanos devem ser considerados e compreendidos a partir de suas relações sociais, que são constituídas historicamente: "O homem é no sentido mais literal, um zoon politikon (ser social, animal social), não só animal social, mas animal que só pode isolar-se em sociedade" (Marx, 1985, p. 104). 
society, we assume the concept production of nature as central to our analysis, understanding that how the biophysical processes present in each place results from the interference of this society. And that, even if the nature has, on some level, an independent working man, the knowledge of this operation is applied by society for purposes defined socially. Analysis of the establishment of protected areas in Brazil reveals a close relationship between the expansion of the agricultural frontier and the isolation of areas designated for conservation. In addition, the management of these areas tends to enter them as the so-called green economy redoubts delimiting products has its own "natural" nature as raw material.

Keywords: Nature. State. Protected areas. Traditional populations. Private property.

\section{Políticas de conservación ambiental en Brasil y mercantilización de la naturaleza}

\section{Resumen}

Este artículo analiza la trayectoria de las políticas de conservación ambiental en Brasil, analizando estas políticas como parte del proceso de expansión de las relaciones de producción capitalistas. Entendiendo que la apropiación y el uso de la naturaleza deben analizarse a partir de la comprensión de las relaciones sociales que caracterizan a la sociedad capitalista, tomamos el concepto de producción de la naturaleza como central en nuestro análisis, entendiendo que la forma en que se presentan los procesos biofísicos en cada lugar resulta de la interferencia de esta sociedad. Y aunque la naturaleza tiene, hasta cierto punto, un funcionamiento independiente del hombre, el conocimiento de este funcionamiento es aplicado por la sociedad con fines socialmente definidos. El análisis del establecimiento de áreas protegidas en el territorio brasileño revela una estrecha relación entre la expansión de la frontera agrícola y el aislamiento de las áreas de conservación. Además, la gestión de estas áreas tiende a insertarlas como baluartes de la llamada Economía Verde, delimitando productos que tienen su propia naturaleza "natural" como materia prima.

Palabras clave: Naturaleza. Estado. Áreas protegidas. Poblaciones tradicionales. Propiedad privada. 


\section{Introdução}

Este artigo discute o desenvolvimento das políticas ambientais, sobretudo aquelas de conservação ambiental, a luz da perspectiva da produção da natureza. Para isso, analisa tais políticas como parte do avanço da lógica da propriedade privada e das relações capitalistas de produção nas regiões em que áreas são delimitadas para fins de conservação.

A construção das políticas de conservação ambiental reflete uma tensão posta na sociedade contemporânea que cerca a produção da natureza no capitalismo. Essa tensão, na verdade, é o indicativo da luta constante em torno da definição de como e para quem se produz a natureza na sociedade. A ideia de produção informa um conjunto de práticas, de regulações, significados e conflitos em torno da apropriação da natureza, e as próprias formas e dinâmicas que daí resultam, sem que se possa ignorar as determinações resultantes dos processos biofísicos (Smith, 1988). A noção de produção da natureza admite a natureza como social, já que ela é modificada no processo produtivo. Além disso, a insere no processo histórico entendido como dialético e contraditório. Assim, essa noção considera que os processos biofísicos estão em relação com os processos sociais e políticos, e, admitindo esse movimento como contraditório, os resultados "indesejados" que a produção social pode criar são também, como sua negação, partes constitutivas do processo produtivo.

A emergência das questões ambientais na sociedade moderna tem levado à elaboração de projetos e políticas públicas que buscam um uso de baixo impacto na natureza. E, grande parte dessas ações é direcionada aos territórios ocupados historicamente por comunidades camponesas e vem tentando ordenar os usos dessas áreas para adequá-los à necessidade de conservação da natureza. Essa necessidade de conservação, entretanto, é antes de tudo um esforço de conservação da sociedade em sua forma vigente (a capitalista), portanto, o esforço de preservação de um certo modo de produção da natureza.

É possível afirmar que no Brasil a questão ambiental, no âmbito da lei, foi influenciada inicialmente pelas concepções de preservação que estavam em voga nos EUA desde o século XIX. A ideia de preservar a natureza surgiu a princípio como resultado de uma preocupação por manter determinadas áreas intocadas frente ao desenvolvimento capitalista em marcha. Mas essa ideia de preservação não criticava a relação da sociedade moderna com a natureza, já que mantinha certas áreas protegidas da destruição visando pesquisas científicas futuras e mesmo criando um "museu" natural para a contemplação da natureza "selvagem". Subjacente a essa ideia de preservação, havia uma noção de natureza apartada do homem. Assim, para assegurar a natureza preservada, era preciso mantê-la sem nenhum uso direto da sociedade. Além disso, o estabelecimento de áreas especiais destinadas à conservação da natureza e à contemplação também pode ser entendido como uma forma de produzir a natureza sob o capitalismo. Ou seja, mesmo quando se cria uma área protegida, se está produzindo a natureza no sentido em que se definem um uso, uma regulação, uma condição para que aquele sistema biofísico natural possa acontecer e se processar em determinado sentido e não em outro. Assim, resulta de uma intervenção humana, configurando uma produção.

$\bigcirc$ resultado objetivo desse movimento de preservação foi o processo de implantação de parques nacionais em todo o mundo como guardiões de uma vida selvagem. No Brasil, como 
em outros países ditos em desenvolvimento, a implantação dessas áreas, sobretudo a partir da década de 1950, chocou-se com territórios ocupados por comunidades camponesas tradicionais (agrícolas e extrativistas), o que trouxe para o centro do debate ambiental, mais claramente, o questionamento da possibilidade da convivência harmoniosa entre a sociedade e a natureza.

$\bigcirc$ estabelecimento de áreas protegidas no Brasil, sobretudo na Amazônia e na Mata Atlântica, a partir do governo militar, refletiu como mais um fator de des-territorialização das comunidades camponesas. Em todo o país, os camponeses lutavam contra a expropriação resultante da expansão da infraestrutura viária, dos projetos agropecuários, hidroelétricos ou de mineração e da especulação imobiliária gerada pela orientação desenvolvimentista daquele período. Ao mesmo tempo, a destruição desenfreada que esse projeto desenvolvimentista ensejava motivou a reação dos ambientalistas para apressar o estabelecimento de áreas protegidas, no anseio, em sua visão, de "salvar" as áreas ainda preservadas. Nesse contexto histórico, desenha-se uma forma de produzir a "natureza conservada" sob o capitalismo que resulta de um entendimento de natureza intocada, natureza natural, ou seja, separada do homem.

É nesse cenário que se intensificam os conflitos entre as comunidades tradicionais camponesas e as unidades de conservação da natureza implantadas pelo governo. Mas intensificavam-se, também, os conflitos de terra entre camponeses, índios, grileiros e fazendeiros. Paulatinamente, essas comunidades vão sendo impedidas de praticar o uso tradicional que faziam dos seus territórios ocupados historicamente.

Como reação à visão radicalmente preservacionista que predominava na política ambiental brasileira até a década de 1980 e à desorganização e violência sofridas pelas comunidades dentro e no entorno de áreas protegidas, intensificam-se movimentos sociais e estudos sociológicos e antropológicos sobre comunidades e a valorização dos modos de vida tradicionais. A etnociência, como ficou conhecida a corrente de estudos dos saberes, práticas e tecnologias das diversas culturas por todo mundo, chamou a atenção dos ambientalistas para a necessidade de considerar que existiam diversas formas de se relacionar com a natureza. Além disso, a valorização do etnoconhecimento permitiu que a conservação da natureza - motivação primeira dos ambientalistas, como movimento - pudesse estar associada a essas práticas tradicionais. Assim, abriu-se a possibilidade histórica da convergência entre a luta das comunidades tradicionais camponesas e aquela do movimento ambientalista. A percepção de que a conservação de remanescentes de diversos ecossistemas estava ligada ao uso diferenciado das comunidades rurais e de que a degradação ambiental na verdade se relacionava à estrutura da sociedade urbana capitalista foi decisiva para que um novo ambientalismo surgisse, e com ele uma nova visão de conservação:

Uma nova modalidade de conservação surgiu da associação entre movimentos sociais que lutam pelo direito de acesso à terra e aos recursos naturais por camponeses, pescadores, ribeirinhos, povos da floresta e de setores do ambientalismo do Terceiro Mundo para os quais a crise ambiental está profundamente associada à crise do modelo de desenvolvimento, à miséria crescente e à degradação ambiental (Diegues, 2008, p. 40). 
Esse ecologismo social ${ }^{2}$ ao qual se refere Diegues entende que a solução dos problemas socioambientais depende de um envolvimento das comunidades rurais e urbanas com as ações e políticas ambientalistas, ao contrário do preservacionismo, que tende a separar os problemas ambientais dos sociais. Segundo Moraes (2000), a partir dos anos 1990, sobretudo após a Rio-92, as questões ambientais passaram a pautar as preocupações geopolíticas dos Estados, o que demandou uma carga política e econômica, expressa, por exemplo, nos diversos acordos internacionais sobre temas ambientais e mesmo no detalhamento da política e legislação ambiental. Entretanto, por outro lado, a possibilidade de conciliação entre desenvolvimento econômico e conservação ambiental será delimitada pela crença de que as soluções para os efeitos indesejados do sistema capitalista passam pela sua integração no próprio mercado.

\section{A natureza como estratégia de acumulação}

O período em que fica mais evidente uma "crise ambiental" e cujas soluções passam a ser tratadas no âmbito do mercado, coincide justamente com a consolidação da globalização do capital e sua guinada neoliberal. Segundo Harvey (2004), esse estágio do desenvolvimento capitalista, em que sua expansão em escala mundial adquire novos contornos, é o resultado da administração de um momento crítico do capital o qual será "equacionado" por meio de uma reordenação espaço-temporal. Nessa reordenação, marcada fortemente pelo comando do capital financeiro, a "crise ambiental" adquire especial importância porque se torna a justificativa para um conjunto de políticas e ações criadoras de mercados e investimentos.

A partir da teoria da tendência de queda da taxa de lucro proposta por Marx (1985), Harvey (2004, p. 78) argumenta que o capitalismo tende a produzir crises crônicas de sobreacumulação, as quais se caracterizam por "excedentes de capital (em termos de mercadoria, moeda e capacidade produtiva) e excedentes de força de trabalho lado a lado, sem que haja aparentemente uma maneira de conjugá-los lucrativamente a fim de realizar tarefas socialmente úteis". A revalorização desses excedentes passa por encontrar novas maneiras lucrativas de absorvê-los, o que abre caminho para a produção e reconstrução de novos espaços e a criação de novas mercadorias. Entretanto, a busca contínua pela acumulação leva à necessidade de destruir investimentos passados (em termos de trabalho e capital) para criar novas frentes de investimento, absorvendo os excedentes e dinamizando a economia.

Esse processo de desvalorização e destruição integra, segundo Harvey (2004), os mecanismos de "acumulação por espoliação". O geógrafo inglês entende que os mecanismos de criação de capital, descritos por Marx (1985) como característicos do processo de acumulação primitiva, são sistematicamente renovados e aprimorados, e, portanto, permanecem ainda hoje como uma força contínua na geografia histórica da acumulação do capital. Assim, concordando

2 Diegues usa a expressão ecologismo social para designar o conjunto de movimentos ambientalistas e de tendências teóricas relativas à ecologia política que articulam os problemas ambientais aos problemas sociais, opondo-o, ao mesmo tempo, ao que chama de ecologismo preservacionista: "enquanto o ecologismo preservacionista tem tendência a separar os aspectos sociais e ambientais, baseando sua estratégia na criação de parques sem gente, no controle demográfico, etc., o ecologismo social afirma as interligações entre o meio ambiente e os problemas sociais (desemprego, migração, expansão do capital e ameaça aos modos de vida de comunidades tradicionais, indígenas, etc.), propondo estratégias de envolvimento das comunidades locais rurais e urbanas na solução dos problemas socioambientais" (Diegues, 2008, p. 161). Como veremos, a expressão ecologismo social seria semelhante a socioambientalismo, nos termos de Santilli (2005). 
com Hannah Arendt (1989), para quem o imperialismo é o meio pelo qual o capital reequilibra seu desequilíbrio crônico, Harvey (2004) chama atenção para o fato de que a solução das crises inerentes ao sistema passa pela busca de algo exterior a ele. Entretanto, esse "exterior" pode ser a integração de formações sociais não capitalistas de produção ou de setores ainda não proletarizados do próprio capitalismo; mas também pode ser criado ativamente pelo sistema por meio da destruição de espaços e investimentos resultantes de uma onda anterior de produção capitalista.

A acumulação por espoliação, portanto, segundo Harvey (2004), ocorre seguindo o que chamou de uma dialética "interior-exterior" na qual as externalidades, na verdade, são geradas pela própria dinâmica contraditória capitalista. Assim, longe de estar circunscrito a um período histórico específico, o processo de formação de capital estaria no cerne do desenvolvimento capitalista e hoje se apresenta por meio de novas formas de acumulação por espoliação:

A escalada da destruição dos recursos ambientais globais (terra, ar, água) e degradações proliferantes de habitats, que impedem tudo exceto formas capital-intensivas de produção agrícola, também resultaram na mercadificação por atacado da natureza em todas as suas formas. A transformação em mercadoria de formas culturais, históricas e da criatividade intelectual envolve espoliações em larga escala [...]. A corporativização e privatização de bens até agora públicos (como as universidades), para não mencionar a onda de privatizações (da água e de utilidades públicas de todo gênero) que tem varrido o mundo, indicam uma nova "onda de expropriação das terras comuns" (Harvey, 2004, p. 123).

Nesse sentido, a degradação ambiental resultante da história de apropriação e produção da natureza no capitalismo, entendida na sociedade moderna como externalidade indesejada do processo produtivo, decorre, na verdade, dessa dinâmica contraditória. E é por isso que pode ser considerada internas ao processo de produção capitalista. Como destaca Harvey (2004) no excerto acima, essa degradação integra o processo de criação de ativos econômicos tanto pela exploração dos recursos naturais como pela transformação dos resultados indesejados dessa exploração em novas mercadorias e mercados. Para Chesnais e Serfati (2003, p. 42), a "crise ambiental" nada mais é que uma crise decorrente do capitalismo, na medida em que a degradação ao meio ambiente resulta da necessidade do capital de colocar "para fora e para a frente [...] as consequências das contradições que são, exclusivamente, suas, no sentido de que surgiram das relações de produção e de propriedade que o fundam".

Ancoradas na ideologia da sustentabilidade, as propostas de solução para as mazelas decorrentes do uso intensivo dos recursos naturais - fruto da consolidação da produção capitalista da natureza - estarão circunscritas a medidas que não refutam a lógica contraditória do funcionamento do capitalismo e, além disso, serão postas em prática num cenário em que a financeirização comanda o desenvolvimento.

A busca pelas soluções, então, se manteve no patamar do incremento tecnológico, reafirmando a noção de "dominação da natureza" que acompanha a sociedade moderna. Nesse sentido, a partir dos anos 1970, parte dos cientistas passou a dedicar seus estudos diretamente ao controle ou à mitigação de riscos, e, da parte dos Estados, viu-se o surgimento de uma gama 
de políticas ambientais. Mas a contradição interna ao próprio desenvolvimento capitalista levou à instrumentalização cada vez maior da natureza e a seu tratamento a partir da lógica do lucro:

No plano econômico, o capital transforma as poluições industriais, bem como a rarefação e/ou a degradação de recursos, como a água e até o ar, em "mercados", isto é, em novos campos de acumulação. [...] o capital entende fazer um mercado da "reparação" das degradações ecológicas. Longe de afetar sua reprodução como capital, essas se tornarão uma imensa fonte de lucros e de sustentação dos preços das ações (Chesnais; Serfati, 2003, p. 43-44).

A objetividade da relação do capital com a natureza se expressa na escalada da sua mercantilização. Assim, se antes, à exceção da terra e alguns produtos naturais de consumo direto, a natureza era concebida sobretudo como fonte de recursos que seriam transformados no processo produtivo em outras mercadorias, agora, a própria "natureza natural" e seus processos biofísicos se constituem como mercadoria, ativo e dispositivo gerador de serviços. E os negócios que essa natureza tem originado passam a ser realizados nos mercados financeiros. Nesse sentido, a natureza passou a ser entendida como uma estratégia de acumulação (Smith, 2007).

As consequências desse aprofundamento da produção da natureza no capitalismo são a interferência cada vez maior do mercado na delimitação de políticas ambientais e, nesse sentido, da política de "conservação ambiental". Em seu artigo "Whose nature, whose culture? Private productions of space and the preservation of nature", Cindi Katz (2005) analisa as consequências de se conceber a natureza como estratégia de acumulação para as políticas de conservação ambiental e as práticas de restauração ambiental. A autora critica a noção de natureza intocada mostrando como as ações de conservação que isolam "áreas naturais" promovem a continuidade da destruição em outras áreas, geralmente próximas às supostamente preservadas, e ainda não logram preservar essa que foi escolhida para esse fim. Além disso, demonstra o racismo ambiental que orienta as políticas de conservação, uma vez que são as áreas pobres, historicamente exploradas, que são sistematicamente "bloqueadas" pela presença de biodiversidade para que, em outra parte do globo, as multinacionais continuem explorando os recursos naturais. E mais, os novos mercados de natureza abrem a possibilidade de certas empresas ganharem duas vezes, com os chamados serviços ambientais. As empresas que promovem o consumo de recursos e geram as "externalidades" na forma de gases de efeito estufa, por exemplo, são as mesmas que receberão os lucros do comércio dos serviços que a biodiversidade pode gerar.

Se aceitarmos o argumento da produção da natureza, podemos entender que, como prática da sociedade moderna, a conservação ambiental produz a natureza de forma específica uma "natureza conservada" -, a qual se apoia na ideia de natureza intocada. Nesse sentido, a conservação propõe a reprodução (a continuidade) da vida, mas, entendendo a relação dialética que envolve esse processo, a questão central que se coloca é como e para quem se produzirá tal "natureza conservada"?

Como veremos, a trajetória das políticas ambientais no Brasil levou a um "reconhecimento" das comunidades tradicionais como importantes para a conservação, mas a orientação 
preservacionista dessas políticas não deixou de ser uma tendência. Além disso, se aquele ecologismo social - que ressalta a necessidade de se respeitarem as comunidades tradicionais -, aliado à luta política dessas comunidades ao longo das últimas décadas, resultou numa conquista de direitos, expressa inclusive em acordos internacionais (especialmente a Convenção 169 da OIT), por outro lado, a reprodução desses povos e de suas formas de produção da natureza se desenrola num cenário mais amplo, onde a "natureza conservada" é criada e reproduzida como uma mercadoria.

\section{Políticas de conservação ambiental no Brasil na esteira da expansão da lógica da mercadoria}

A definição de políticas públicas voltadas para questões ambientais no Brasil está bastante relacionada com o desenvolvimento político econômico do país ao longo do século XX, mas também com as lutas por território de populações camponesas tradicionais em diferentes pontos do país. Essas políticas são aquelas que versam sobre proteção, conservação e uso dos recursos naturais (Silva-Sánchez, 2010).

Cuidados de manejo visando a manutenção da fertilidade e a reprodução da biodiversidade - o que podemos chamar de práticas conservacionistas - estão presentes em diferentes formas de produção e reprodução da natureza. Entretanto, a proteção e conservação do meio ambiente entendidas como práticas desenvolvidas em resposta ao impacto gerado pelo consumo desregulado e degradação dos recursos naturais são necessidades que se impõem no contexto mais geral de certo tipo de relação com a natureza. Assim, as políticas ambientais devem ser entendidas como parte da relação contraditória entre a sociedade e a natureza, estabelecendo-se circunscritas ao predomínio da produção capitalista da natureza.

No Brasil, as primeiras políticas ambientais foram estabelecidas nos anos 1930, sob o governo de Getúlio Vargas. Nessa década, foram criados três Parques Nacionais (Itatiaia-RJ, Serra dos Órgãos-RJ e Iguaçu-PR) com o objetivo de proteger remanescentes florestais do domínio da Mata Atlântica. Inspiradas no modelo estadunidense, essas áreas foram decretadas como públicas e intocadas, justamente no período em que os estados do Sudeste e do Sul passavam por acelerado processo de urbanização e que as atividades ligadas à indústria de base e criação de infraestrutura recebiam incentivos estatais e fiscais.

Assim, entre as décadas de 1930-60, a criação de áreas protegidas seguiu o eixo do desenvolvimento industrial e urbano do país, o que se verifica pelo número de unidades de conservação (UC) implementadas nos estados-alvo das políticas desenvolvimentistas conforme o Quadro 1, 12 de 23 estavam na Mata Atlântica. A criação de áreas protegidas surge como uma face da especificidade da apropriação e produção da natureza que vinha assumindo o desenvolvimento capitalista no país. A escolha de poupar áreas do consumo dos recursos para a industrialização em marcha pressupõe que esse consumo necessário será direcionado e incentivado em outros espaços. Por isso, a mesma política que começa a impor regras para o uso dos recursos pelas atividades produtivas define a criação de UC como estratégia de proteção da natureza. 


\section{Quadro 1 - Unidades de conservação federais criadas entre 1930 e 1961}

\begin{tabular}{|c|c|c|c|}
\hline data da criação & unidade de conservação & estado & domínio \\
\hline 1934 & Parna Itatiaia & RJ & \multirow{5}{*}{ Mata Atlântica } \\
\hline \multirow{2}{*}{1939} & Parna Iguaçu & $\mathrm{PR}$ & \\
\hline & Parna Serra dos Órgãos & RJ & \\
\hline 1943 & Rebio Sooretama & ES & \\
\hline & Flona Tijuca & RJ & \\
\hline 1940 & Flona Araripe-Apodi & $\mathrm{CE}$ & \multirow[b]{2}{*}{ caatinga } \\
\hline \multirow{2}{*}{1948} & Parna de Paulo Afonso (extinto) & $\mathrm{AL} / \mathrm{PE} / \mathrm{BA}$ & \\
\hline & Rebio Córrego do Veado & ES & Mata Atlântica \\
\hline 1950 & Rebio da Serra Negra & $\mathrm{PE}$ & caatinga \\
\hline 1953 & Rebio de Nova Lombardia & ES & \multirow{3}{*}{ Mata Atlântica } \\
\hline \multirow{4}{*}{1959} & Flona de Jaíba & $\mathrm{MG}$ & \\
\hline & Parna Aparados da Serra & $\mathrm{RS} / \mathrm{SC}$ & \\
\hline & Parna de Ubajara & CE & caatinga \\
\hline & Parna do Araguaia & $\mathrm{TO}$ & \multirow{4}{*}{ cerrado } \\
\hline \multirow{9}{*}{1961} & Parna das Emas & $\mathrm{GO} / \mathrm{MT}$ & \\
\hline & Parna Tocantins (Chapada dos Veadeiros) & $\mathrm{GO}$ & \\
\hline & Parna Brasilia & $\mathrm{DF}$ & \\
\hline & \begin{tabular}{|l|} 
Parna do Xingu \\
\end{tabular} & MT & Amazônia \\
\hline & Parna Sete Quedas (extinto) & $\mathrm{PR}$ & \multirow{3}{*}{ Mata Atlântica } \\
\hline & \begin{tabular}{|l|} 
Parna São Joaquim \\
\end{tabular} & $\mathrm{SC}$ & \\
\hline & Parna Monte Pascal & $\mathrm{BA}$ & \\
\hline & \begin{tabular}{|l} 
Parna Sete Cidades \\
\end{tabular} & $\mathrm{PI}$ & caatinga \\
\hline & Flona Caxiuanã & PA & Amazônia \\
\hline
\end{tabular}

obs: Parna $=$ parque nacional, Flona $=$ floresta nacional, Rebio $=$ reserva biológica

fontes: Alves (1996), Diegues e Vianna (1995) e ICMBio ([s.d.]).

Até meados dos anos 1950, a criação de unidades de conservação se concentrou no eixo urbanizado do Sudeste-Sul e, a partir de então, seguiu o deslocamento do desenvolvimento e da população para o interior do país. Assim, a década seguinte foi marcada pela criação de UC na região Centro-Oeste ${ }^{3}$, reflexo da construção de Brasilia, e os anos 1970-80, pelo boom de unidades de conservação na região amazônica.

Durante os governos militares, a intensificação das políticas desenvolvimentistas fez aumentar a presença de indústrias poluidoras no país, associadas aos Planos Nacionais de Desenvolvimento (PND), os quais envolveram uma série de grandes obras de infraestrutura. A abertura ao capital internacional, sobretudo a partir da década de 1970, colocou o Brasil na rota dos territórios aos quais se dirigem os excedentes de capital dos países centrais do capitalismo. A partir de um governo autoritário e repressor dos movimentos sociais, o alinhamento do país com o desenvolvimento capitalista internacional (comandado pelos EUA) teve impacto significativo na apropriação dos recursos naturais e em degradações de vários tipos.

$\bigcirc$ alvo das ações dos governos militares foi principalmente a região amazônica, que se estende do Mato Grosso aos estados da região Norte, justificado, no plano ideológico, pelo projeto de integração nacional. A exploração de madeira, os projetos agropecuários, a implantação de

3 Conforme o Quadro 1, foram criadas 13 unidades de conservação entre 1959 e 1961, cinco das quais no Centro-Oeste: os parques nacionais Araguaia, Emas, Tocantins, Brasília e Xingu. 
garimpos e a abertura de estradas como a Transamazônica, a Perimetral Norte etc. aumentaram sensivelmente o desmatamento nessa região, além de acirrar ou criar conflitos de terra envolvendo indígenas, posseiros (muitos migrantes do Nordeste atraídos por esses projetos) e grileiros.

Concomitante ao consumo dos recursos naturais, acelerado a partir do projeto modernizante do governo militar, cresce também a criação de unidades de conservação em todo território nacional. Como mostra o Quadro 2, além de parques nacionais, são implantadas outras categorias de UC (reservas biológicas, estações ecológicas, florestas nacionais, num total de 87 entre 1970 e 1992), algumas, mais restritivas à presença humana, destinadas apenas à pesquisa científica. ${ }^{4}$ Como observa Barreto Filho (2004), na região amazônica, a criação de UC de proteção integral ganhou grande impulso ${ }^{5}$ durante as décadas de 1970-80, o que fazia parte da estratégia dos governos militares de integrar o território nacional.

Verifica-se, assim, um grande progresso de medidas conservacionistas, tanto administrativas quanto jurídicas, ao tempo dos governos Geisel e Figueiredo. Essa coincidência é tanto mais significativa quanto aparentemente contraditória, pois esse ainda é o período de expansão induzida da fronteira agrícola para a Amazônia - via projetos de colonização oficiais - e de criação de localizações privilegiadas para a valorização de capitais privados e o crescimento "polarizado" via subsídios e investimentos públicos no setor de infraestrutura regional. Foi, portanto, o mesmo contexto histórico em que o regime militar levou adiante as políticas que têm sido responsabilizadas por efeitos sociais e ambientais deletérios na região (Davis, 1977), ${ }^{6}$ aquele em que mais se avançou em termos de medidas conservacionistas por meio da criação de UCs de Proteção Integral (Barreto Filho, 2004, p. 59).

É interessante perceber como a intensificação do uso dos recursos naturais, resultado da expansão espacial da fronteira agrícola, sobretudo no Norte e no Nordeste, é acompanhada pelo aumento não só do número de áreas protegidas, mas de sua natureza restritiva. Fica evidente que o caráter preservacionista que foi assumindo a política de conservação decorre da expansão da lógica da propriedade privada que, ao estabelecer as relações de produção capitalistas, parcelando e mercantilizando a terra para implantar projetos agropecuários e de infraestrutura, define também as áreas que deveriam permanecer isoladas desse uso. É nesse sentido que podemos afirmar que a necessidade de conservação ambiental se impõe como parte da forma como a natureza vai sendo apropriada pelo processo produtivo capitalista. E a definição de unidades de conservação se processa no contexto em que a terra se torna mercadoria, portanto, a destinação para conservação ambiental acontece a partir da apreensão dessa "primeira natureza" pela lógica do mercado.

4 As estações ecológicas (Esecs) e as reservas biológicas (Rebios) são unidades de conservação mais restritivas que os parques nacionais, pois se destinam a pesquisa científica e/ou a medidas de preservação e só admitem visitação com objetivo educacional (no caso das Esecs).

5 Em 1974, criam-se o Parque Nacional da Amazônia, com 994 mil hectares em Itaituba (PA), e a Floresta Nacional do Tapajós. Conforme o Quadro 2, entre 1971 e 1992, foram criados 21 parques nacionais, sete dos quais na região amazônica, e 19 reservas biológicas, oito delas na mesma região. Entre 1981 e 1990, foram 21 estações ecológicas, sendo oito na Amazônia Legal. O Quadro também mostra que, das 26 florestas nacionais criadas entre 1974 e 1992, 24 estão na região amazônica.

6 DAVIS, S. The victims of the miracle: development and the indians of Brazil. Cambridge: Cambridge University Press, 1977. 
Quadro 2 - Unidades de conservação federais criadas entre 1970 e 1992

\begin{tabular}{|c|c|c|c|c|}
\hline categoria & data & nome da UC & estado & domínio \\
\hline \multirow{21}{*}{ Parque Nacional } & 1971 & Serra da Bocaina & RJ & Mata Atlântica \\
\hline & 1972 & Serra da Canastra & MG & Mata Atlântica \\
\hline & 1974 & Amazônia & PA/AM & Amazônia \\
\hline & \multirow{3}{*}{1979} & Pico da Neblina & AM & Amazônia \\
\hline & & Serra da Capivara & PI & caatinga \\
\hline & & Pacaás Novos & $\mathrm{RO}$ & Amazônia \\
\hline & \multirow{2}{*}{1980} & Cabo Orange & $\mathrm{AP}$ & Amazônia* \\
\hline & & Jaú & AM & Amazônia \\
\hline & \multirow{2}{*}{1981} & Lençóis Maranhenses & MA & cerrado* \\
\hline & & Pantanal Mato-grossense & MT & pantanal \\
\hline & 1983 & Marinho de Abrolhos & $\mathrm{BA}$ & Mata Atlântica \\
\hline & 1984 & Serra do Cipó & MG & cerrado \\
\hline & 1985 & Chapada Diamantina & BA & caatinga \\
\hline & 1986 & Lagoa do Peixe & RS & Mata Attântica* \\
\hline & 1988 & Marinho de F. de Noronha & $\mathrm{PE}$ & Marinho Costeiro \\
\hline & \multirow{5}{*}{1989} & Chapada dos Guimarães & MT & cerrado \\
\hline & & Grande Sertão Veredas & $\mathrm{MG}$ & cerrado \\
\hline & & Superagui & $\mathrm{PR}$ & Mata Atlântica* \\
\hline & & Serra do Divisor & $\overline{A C}$ & Amazônia \\
\hline & & Monte Roraima & RR & Amazônia \\
\hline & 1992 & Serra Geral & $\mathrm{RS} / \mathrm{SC}$ & Mata Atlântica \\
\hline \multirow{20}{*}{ Reserva Biológica } & & & & total Parna: \\
\hline & 1974 & Poço das Antas & RJ & Mata Atlântica \\
\hline & \multirow{3}{*}{1979} & Atol das Rocas & $\mathrm{RN}$ & Marinho Costeiro \\
\hline & & Jaru & $\mathrm{RO}$ & Amazônia \\
\hline & & Rio Trombetas & PA & Amazônia \\
\hline & \multirow{2}{*}{1980} & Lago Piratuba & $\mathrm{AP}$ & Amazônia \\
\hline & & Uma & $\mathrm{BA}$ & Mata Atlântica \\
\hline & \multirow{2}{*}{1982} & Abufari & AM & Amazônia \\
\hline & & Guaporé & $\mathrm{RO}$ & Amazônia \\
\hline & 1983 & Saltinho & $\mathrm{PE}$ & Mata Atlântica \\
\hline & 1984 & Comboios & $\overline{E S}$ & Mata Atlântica \\
\hline & \multirow{2}{*}{1988} & Gurupi & $\mathrm{MA}$ & Amazônia \\
\hline & & Santa Isabel & SE & Mata Atlântica \\
\hline & \multirow{4}{*}{1989} & Córrego Grande & ES & Mata Atlântica \\
\hline & & Tapirapé & $\mathrm{PA}$ & Amazônia \\
\hline & & Tinguá & RJ & Mata Atlântica \\
\hline & & Pedra Talhada & $\mathrm{PE} / \mathrm{AL}$ & Mata Atlântica \\
\hline & \multirow{3}{*}{1990} & Guariba & $\mathrm{PB}$ & Mata Atlântica \\
\hline & & Marinha do Arvoredo & $\mathrm{SC}$ & Mata Atlântica \\
\hline & & Uatumã & AM & Amazônia \\
\hline
\end{tabular}




\begin{tabular}{|c|c|c|c|c|}
\hline categoria & data & nome da UC & estado & domínio \\
\hline & & & & total Rebio: 19 \\
\hline \multirow{21}{*}{ Estação Ecológica } & \multirow{8}{*}{1981} & Maracá-Jipioca & AP & Amazônia \\
\hline & & Rio Acre & $\mathrm{AC}$ & Amazônia \\
\hline & & Maracá & $\mathrm{RR}$ & Amazônia \\
\hline & & Anavilhanas & AM & Amazônia \\
\hline & & Aracuri-Esmeralda & $\mathrm{RS}$ & Mata Atlântica \\
\hline & & Uruçuí-Uma & $\mathrm{PI}$ & cerrado \\
\hline & & Iquê & MT & cerrado \\
\hline & & Taiamã & MT & pantanal \\
\hline & \multirow{5}{*}{1982} & Jari & $\mathrm{PA} / \mathrm{AP}$ & Amazônia \\
\hline & & Caracarai & $\mathrm{RR}$ & Amazônia \\
\hline & & Serra das Araras & MT & cerrado \\
\hline & & Seridó & RN & caatinga \\
\hline & & Guaraqueçaba & PR & Mata Atlântica \\
\hline & \multirow{2}{*}{1985} & Niquiá & $\mathrm{RR}$ & Amazônia \\
\hline & & Juami-Japurá & AM & Amazônia \\
\hline & \multirow{2}{*}{1986} & Tupiniquins & $\mathrm{SP}$ & Mata Atlântica \\
\hline & & Taim & $\mathrm{RS}$ & pampa \\
\hline & \multirow{3}{*}{1987} & Tupinambás & SP & Mata Atlântica \\
\hline & & Carijós & $\mathrm{SC}$ & Mata Atlântica \\
\hline & & Pirapitinga & $\mathrm{MG}$ & cerrado \\
\hline & 1990 & Tamoios & RJ & Mata Atlântica \\
\hline & & & & total Esec: 21 \\
\hline \multirow{16}{*}{ Floresta Nacional } & 1974 & Tapajós & PA & Amazônia \\
\hline & 1984 & Jamari & $\mathrm{RO}$ & Amazônia \\
\hline & 1986 & Mário Xavier & RJ & Mata Atlântica \\
\hline & \multirow{4}{*}{1988} & Ibirama & $\mathrm{SC}$ & Mata Atlântica \\
\hline & & Macauã & $\mathrm{AC}$ & Amazônia \\
\hline & & Purus & AM & Amazônia \\
\hline & & Bom Futuro & $\mathrm{RO}$ & Amazônia \\
\hline & \multirow{9}{*}{1989} & Amapá & AP & Amazônia \\
\hline & & Amazonas & AM & Amazônia \\
\hline & & Mapiá-Inauini & AM & Amazônia \\
\hline & & Pari Cachoeira I (extinta)** & AM & Amazônia \\
\hline & & Pari Cachoeira II (extinta) ** & AM & Amazônia \\
\hline & & Roraima & $\mathrm{RR}$ & Amazônia \\
\hline & & Saracá Taquera & PA & Amazônia \\
\hline & & Tapirapé/Aquiri & PA & Amazônia \\
\hline & & Tefé & AM & Amazônia \\
\hline
\end{tabular}




\begin{tabular}{|c|c|c|c|c|}
\hline categoria & data & nome da UC & estado & domínio \\
\hline \multirow{11}{*}{ Floresta Nacional } & \multirow{10}{*}{1990} & Cubaté (extinta)** & AM & Amazônia \\
\hline & & Cuiari (extinta)** & AM & Amazônia \\
\hline & & Içanã (extinta)** & AM & Amazônia \\
\hline & & Içana-Aiari (extinta)** & AM & Amazônia \\
\hline & & Piraiauara (extinta)** & AM & Amazônia \\
\hline & & Taracuá I (extinta) ${ }^{* *}$ & AM & Amazônia \\
\hline & & Taracuá II (extinta)** & AM & Amazônia \\
\hline & & Urucu (extinta)** & AM & Amazônia \\
\hline & & Xié (extinta)** & AM & Amazônia \\
\hline & & Rio Preto & ES & Mata Atlântica \\
\hline & 1992 & Ipanema & $\mathrm{SP}$ & Mata Atlântica \\
\hline & & & & total Flona: 26 \\
\hline
\end{tabular}

* O ICMBio classifica essas UC como representantes do Bioma Marinho-Costeiro. Aqui optamos por colocá-las com os domínios florestais a que estão relacionadas, para melhor compreender seu impacto no número total de UC nessas áreas.

** Essas florestas nacionais foram criadas por sucessivos decretos e extintas no governo Collor pelo decreto de 5 de setembro de 1991. No entanto, mantivemo-las no Quadro por serem representativas do número de UC promulgadas na região amazônica no período.

fontes: Alves (1996), Diegues e Vianna (1995) e ICMBio ([s.d.]).

\section{Os limites da reação socioambientalista frente às contradições da produção capitalista da natureza}

Nos anos 1980, o estabelecimento das UC no país seguia identificado com o modelo estadunidense de áreas protegidas, o qual concebe as "áreas naturais" como selvagens e intocadas. Entretanto, a maioria das UC do Brasil foi fundada em territórios de comunidades camponesas tradicionais, cujas terras estavam parcialmente integradas ao desenvolvimento de relações capitalistas de produção. Durante as décadas de regime militar, as UC no país foram implantadas a despeito da presença dessas comunidades, mas a morosidade na implantação da gestão dessas áreas manteve, em muitos casos, uma situação de sobreposição desapercebida, uma vez que o poder público não se fazia presente. A partir década de 1980, com o incremento da política ambiental, os quadros de fiscalização passam a coibir as práticas tradicionais (agricultura e extrativismo), o que faz emergir o conflito entre diferentes formas de produzir a natureza.

A invisibilidade dessas comunidades aos olhos do Estado se deve, de um lado, à própria visão de conservação que, uma vez derivada do entendimento moderno de natureza, ${ }^{7}$ só concebe os remanescentes florestais como recursos naturais que têm sentido no processo produtivo capitalista, ainda que reservados a contemplação ou pesquisa científica - necessidades da sociedade moderna. Da mesma maneira, no projeto desenvolvimentista, baseado no modelo da monocultura e do latifúndio, não há lugar para a propriedade comum e a pequena agricultura de base familiar camponesa. Partindo dessa premissa, o destino dessas comunidades deveria ser mesmo a proletarização e a superação de formas "arcaicas" de produção.

7 A ideia de natureza que prevalece na sociedade moderna está assentada numa oposição a tudo o que é produzido ou construído pelo homem. Nesse sentido, a natureza é concebida como fornecedora de recursos a ser usados no processo produtivo. 
A investida do poder público para controlar e fiscalizar o uso da terra e dos recursos naturais nas UC levou à criminalização das práticas tradicionais, com um crescimento do número de ocorrências policiais envolvendo moradores dessas áreas. Mas também contribuiu contraditoriamente para o crescimento da organização local e regional das comunidades tradicionais por meio da criação de associações de moradores e sindicatos na tentativa de assegurar o direito à posse da terra. Da parte do Estado, emergia uma nova visão, que entendia que essas comunidades deviam ser consideradas parte da conservação, uma vez que seus modos de vida teriam concorrido para a proteção dos remanescentes florestais.

É desse encontro entre movimentos de comunidades locais, intelectuais e agentes do Estado ligados ao movimento ambientalista que nasceu, segundo Santilli (2005), o socioambientalismo brasileiro (ou o ecologismo social, nos termos de Diegues). E, sobretudo a partir da influência e dos resultados da Conferência Mundial para o Meio Ambiente (Rio-92), "os conceitos socioambientais passaram, claramente, a influenciar a edição de normas legais" (Santilli, 2005, p. 12). Segundo a autora, esses conceitos se referem justamente à consideração de que as políticas ambientais (entre elas, as de criação e gestão de áreas protegidas como as UC) devem "incluir e envolver as comunidades locais, detentoras de conhecimentos e de práticas de manejo ambiental" (Santilli, 2005, p. 12). Assim, o socioambientalismo inclui a justiça social na ideia de sustentabilidade:

[O socioambientalismo] desenvolveu-se a partir da concepção de que em um país pobre e com tantas desigualdades sociais, um novo paradigma de desenvolvimento deve promover não só a sustentabilidade estritamente ambiental - ou seja, a sustentabilidade de espécies, ecossistemas e processos ecológicos - como também a sustentabilidade social - ou seja, deve contribuir também para a redução da pobreza e das desigualdades sociais e promover valores como justiça social e equidade (Santilli, 2005, p. 14).

Todavia, se de fato crescia um entendimento mais amplo da questão ambiental na sociedade brasileira, por outro lado, uma visão mais estreita e restrita à "proteção de espécies e recursos naturais" seguia forte e, até certo ponto, predominava entre os legisladores. A oposição entre visões de conservação que circulam no campo de lutas ambientalista durante o final da década de 1980 e nos anos 1990 se expressa no resultado da assembleia constituinte, assim como na discussão sobre a Lei do Sistema Nacional de Unidades de Conservação (Snuc). O movimento ambientalista consegue avanços quanto à forma como é tratado o meio ambiente no texto final da Constituição de 1988. Entretanto, ainda que a Constituição direcione as políticas ambientais a um caráter difuso e incentive a participação popular na discussão dessas políticas, o que se seguiu, ao longo dos anos 1990, no que tange à política de conservação foi a prioridade da implantação de novas unidades de conservação de proteção integral (Mapa 1) e de programas de fiscalização nas unidades já existentes. 


\section{Mapa 1 - UC de proteção integral, Resex e RDS criadas a partir de 1990}

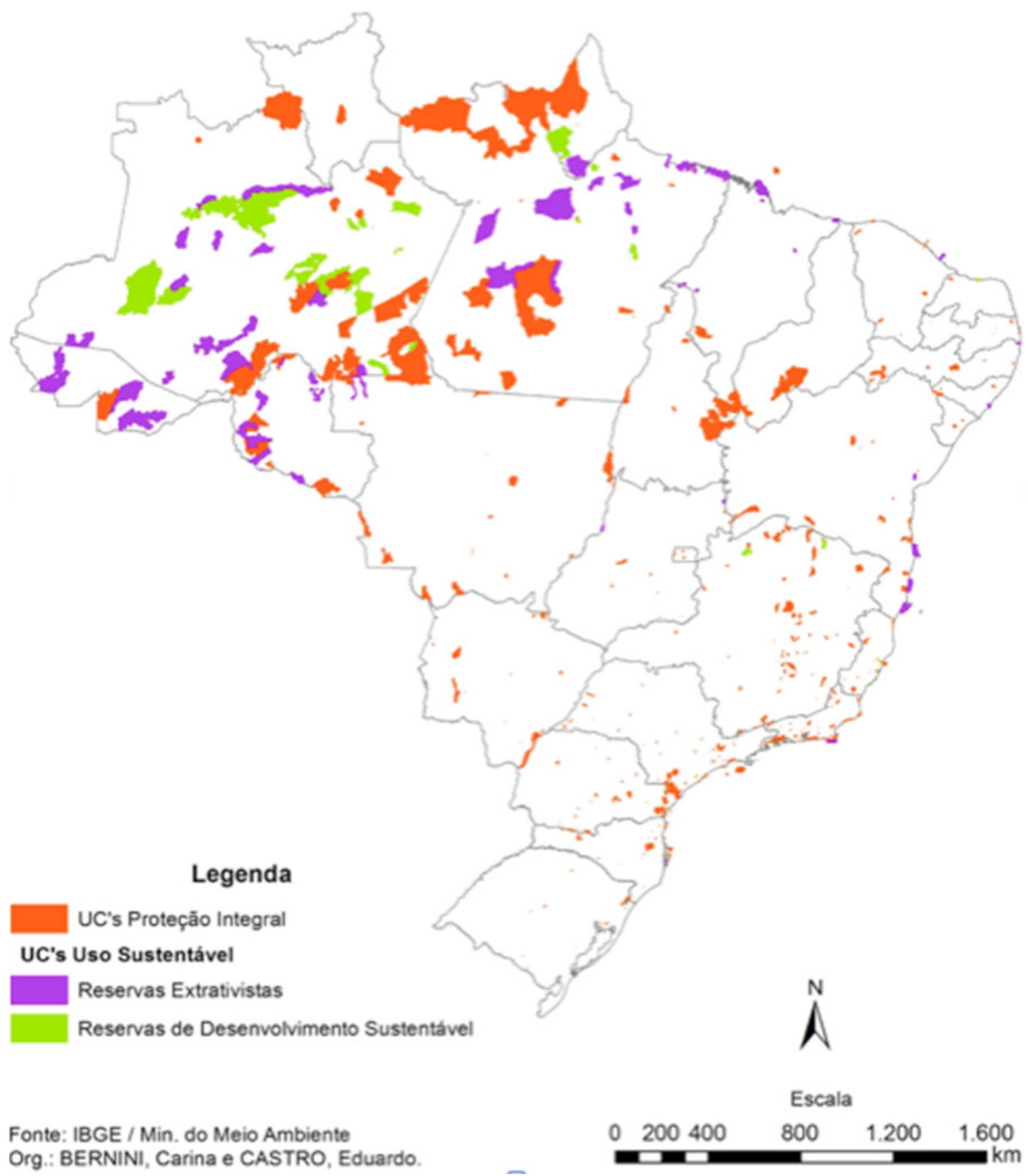

Por outro lado, a influência das discussões da Rio-92 e a pressão dos movimentos sociais locais, sobretudo de populações tradicionais moradoras em UC, resultou na criação de categorias de unidades de conservação de uso sustentável como as reservas extrativistas (Resex) e as reservas de desenvolvimento sustentável (RDS). A Resex, principalmente, foi proposta pelo movimento dos seringueiros do Acre a partir da sua experiência de luta e resistência para manter a floresta sob o domínio coletivo das familias seringueiras. Luta essa, contra a transformação da terra em mercadoria para a criação de gado na região amazônica. Assim, os conflitos nas UC e a ascensão dos movimentos locais no campo de lutas do ambientalismo deixam mais claro que as áreas de conservação são resultado do manejo de comunidades tradicionais que se reproduzem no limite da propriedade privada, ou seja, comunidades que vêm desenvolvendo historicamente relações sociais de apropriação e produção que não correspondem àquelas legitimadas pelo estatuto da propriedade privada. 
$\bigcirc$ incremento das discussões acerca das políticas ambientais no Brasil deve ser analisado também como parte do contexto político internacional que passa a valorizar cada vez mais a dimensão ambiental das políticas de desenvolvimento. E, de acordo com Lima (2008), a priorização da implementação do Snuc poderia ser entendida como uma mediação entre processos mais globais - reveladores da chamada ordem ambiental internacional ${ }^{8}$ - e dimensões da formação socioespacial brasileira. A escolha do Snuc como caminho para o cumprimento de metas de conservação se evidencia pela disponibilidade de fundos internacionais para a conservação que se dirigem prioritariamente para as políticas territoriais de implantação de UC (Lima, 2008).

Assim, como destaca Bim (2012), é justamente na discussão da lei do Snuc que ficará claro o desafio de se tratar da questão das populações tradicionais em áreas protegidas. Entre 1989 e 2000, quando a lei foi finalmente promulgada, emergiram as diferenças de visão dos ambientalistas quanto à conservação ambiental. As questões da permanência das comunidades camponesas tradicionais dentro das UC e da importância do seu papel na conservação foram temas recorrentes nesses debates que dividiam preservacionistas e conservacionistas.

Ancorados na visão ecocêntrica, os preservacionistas defendiam que as UC deveriam ser isoladas de qualquer alteração antrópica, servindo apenas à pesquisa científica que "auxiliasse a própria conservação". Nesse caso, as comunidades deveriam ser retiradas das áreas destinadas à conservação e reassentadas em outro lugar, cabendo exclusivamente ao Estado a criação e gestão das UC. Já os conservacionistas, baseados no ecologismo social, entendiam que as comunidades locais deveriam ser incluídas na conservação a partir de processos participativos e da valorização de práticas agrícolas/extrativistas tradicionais, pois assim poderiam concorrer para a proteção da natureza.

No entanto, tanto o preservacionismo como o conservacionismo expressam a necessidade de conservação ambiental que é derivada da produção capitalista da natureza e, nesse sentido, reproduzem as contradições da relação da sociedade moderna com a natureza. $\bigcirc$ primeiro claramente encara a fundação de áreas protegidas como um mecanismo de isolamento de áreas representativas dos ecossistemas, aceitando e naturalizando o sistema produtivo consumidor de recursos naturais como universal. Nesse sentido, as UC são "um subproduto necessário para a compensação da destruição da natureza produzida pelo processo de modernização industrial. A sociedade de riscos, buscando formas de contrapor-se a si mesma, justifica-se pela necessidade de conservação de ilhas de biodiversidade" (Simões, 2010, p. 35). $\bigcirc$ conservacionismo, por outro lado, entende que a conservação dos remanescentes dos ecossistemas é resultado de um manejo diferenciado de comunidades camponesas tradicionais (assim como de povos indígenas), mas a proposta de "aliança entre os modos de vida tradicionais e a conservação" tende a se ancorar na racionalidade técnico-científica, típica da sociedade moderna. Além disso, os mecanismos criados de valorização dos saberes e práticas acabam por colocá-los a serviço da lógica do mercado.

8 Segundo Ribeiro (2010, p. 1), "nas últimas décadas a temática [ambiental] emergiu como uma das mais importantes preocupações de governos de diversos países do mundo, o que possibilitou a institucionalização da ordem ambiental internacional que visa regular as relações humanas em caráter mundial, envolvendo temas relacionados ao ambiente por meio de protocolos e acordos multilaterais entre países e blocos de países". 
O debate acerca da presença humana em UC e os conflitos entre comunidades tradicionais e áreas protegidas fizeram com que o Snuc levasse em conta o papel dessas comunidades na conservação. Assim, a lei do Snuc (Lei Federal n. 9.985), promulgada em 18 de julho de 2000, inclui como categorias de UC as reservas extrativistas e as reservas de desenvolvimento sustentável, ambas planejadas para ser instituídas em áreas com presença de comunidades agroextrativistas tradicionais. Além disso, o Snuc avança no sentido de considerar as comunidades do entorno e interior de UC (inclusive de proteção integral) participantes da gestão dessas unidades, por meio dos conselhos consultivos e de sua participação na elaboração dos planos de manejo.

O Mapa 1 ilustra a representatividade dessas categorias de UC, frutos das lutas socioambientais e destinadas a territórios de comunidades tradicionais. Também é possível compará-las às UC de proteção integral - criadas a partir de $1990^{\circ}$ - em termos de número e área. É perceptível o predomínio de UC de proteção integral em todo o país, ainda que sejam abundantes e consideráveis em termos de área as Resex e RDS na região amazônica.

Portanto, como afirmamos, mesmo com o avanço do entendimento de que a conservação deveria considerar as formas de produção da natureza de comunidades tradicionais - cuja relação com a terra está pautada no uso comum e no valor de uso -, o que se verificou foi a prevalência de uma política preservacionista, derivada da produção capitalista da natureza.

Por outro lado, mesmo quando considera a participação das comunidades na gestão das UC - o que deve ser entendido como um avanço, sem dúvida -, a lei do Snuc mantém uma visão utilitarista da natureza, condicionando o direito das comunidades camponesas tradicionais ao território à conservação dos recursos naturais. Conservação esta que se define a partir dos desígnios da sociedade moderna e que, como vimos, é intrinsicamente contraditória, já que não critica as bases que fundamentam o modo de produção capitalista, ou seja, a propriedade privada e o valor de troca. Ao contrário, a conservação a acaba sendo mais uma forma de criar mercados para dar vazão aos ativos "sobrantes" do sistema capitalista.

\section{Considerações finais}

As políticas ambientais apontam uma trajetória que dá mais legitimidade ao uso dos recursos e à redução dos danos ambientais causados pelo desenvolvimento (sobretudo industrial) e a entender o meio ambiente como "setor" que perpassa todas as instâncias do desenvolvimento. Nesse sentido, a dimensão ambiental está mais presente no planejamento, seguindo a ideia conservacionista do desenvolvimento sustentável. Isso se materializou com os mecanismos de avaliação e mitigação de impactos, os zoneamentos ecológico-econômicos, os planos de gerenciamento costeiro, o estabelecimento de áreas de conservação associadas ao manejo sustentável da natureza (APA, Resex, RDS) e ainda os mosaicos de áreas protegidas. Segundo Pinheiro (2010, p. 17), tais mecanismos resultam de uma ampliação da perspectiva ambiental para o planejamento e a gestão territorial e, no caso específico das áreas protegidas, o autor

9 Optamos por ilustrar as UC de proteção integral criadas a partir de 1990 porque foi então que se começou a criar Resex (a primeira Resex é a Chico Mendes-AC, de 1990, já a primeira RDS é a Mamirauá-AM, de 1996). Assim, temos uma base de comparação da criação de UC de proteção integral em relação àquelas que admitem comunidades tradicionais.

Foram consideradas as UC criadas de janeiro de 1990 a dezembro de 2016. 
entende que elas passam a ser "indutoras de um processo de desenvolvimento de determinada região e a partir delas se desenham diferentes formas de desenvolvimento territorial".

Pinheiro (2010) chama atenção ainda para o fato de que as novas categorias de manejo de UC derivam da ampliação do conceito de proteção ambiental, no qual as áreas protegidas precisam ter uma relação mais fecunda com o lugar onde se inserem, a partir de mecanismos de participação, deixando de ser encaradas como "ilhas". Entretanto, se, por um lado, são tentativas de romper com o preservacionismo, de outro, na prática, elas se concretizam com base na mediação do mercado, inclusive o financeiro, a partir da implantação de projetos como o de Pagamento por Serviços Ambientais (PSA) ou o de Mecanismos de Desenvolvimento Limpo (MDL), por exemplo.

A partir dos anos 2000, o estabelecimento de unidades de conservação de uso sustentável, sobretudo Resex e RDS, tem sido uma forma de garantir direitos territoriais às comunidades camponesas. Todavia, a gestão dessas áreas revela as contradições de elas terem que se reproduzir sob uma lógica mais ampla, que concebe a conservação como um negócio. Por isso, a implantação de UC ativa o mercado de terras por meio de desapropriações milionárias e cria projetos de gestão e manejo de acordo com a lógica do mercado, mediados por ONG e empresas e financiados por bancos e organismos multilaterais. Isso fere a autonomia das comunidades camponesas na gestão de seus territórios e impõe mudanças significativas a seus modos de apropriação e produção da natureza, aos quais se deve a conservação dos ecossistemas até então. Por outro lado, os negócios envolvendo territórios de comunidades tradicionais podem ensejar a reprodução de processos econômicos que têm lugar em outras escalas, funcionando como moeda de troca para a liberação de mercados e o abatimento de dívidas externas.

Assim, ainda que, a partir dos anos 2000, as UC de uso sustentável tenham passado a integrar a política de conservação, identificamos a tendência do Estado a favorecer os projetos de proteção integral, inclusive no que tange à concessão da administração de serviços à iniciativa privada (sobretudo os relativos à visitação pública). Esse modelo de concessão também é pauta do governo federal a partir das parcerias público-privadas (PPP) e concessões de UC, sobretudo os parques nacionais com grande potencial turístico.

Mesmo que tal concessão tenha a intenção de favorecer comunidades vizinhas às UC com a criação de possíveis postos de trabalho pelas empresas, na sua execução, se revela a lógica econômica, pois tais comunidades não conseguem ser incluídas nesses projetos (ou o são de forma marginal) e terminam não tendo acesso à renda gerada pela exploração desses territórios. Além disso, os projetos de manejo florestal administrados por $\mathrm{N} G$ funcionam para o investimento de capitais de grupos financeiros nacionais e internacionais, o que mostra a relação da conservação com a lógica econômica mais ampla.

A tendência à mercadificação da natureza está expressa na atual revisão do Código Florestal, aprovada em maio de 2012. A nova lei cria mecanismos de compensação apoiados no valor de mercado das áreas naturais a partir de negociações realizadas em bolsas de valores. É o caso da possibilidade de compensação de reserva legal de áreas particulares a partir da compra de cotas de reserva ambiental (CRA) e da desapropriação de terras no interior de UC públicas. 
As recentes mudanças no Código Florestal mostram que as políticas ambientais - tanto aquelas que visam regulamentar o uso dos recursos naturais como as que versam sobre proteção da natureza - vão alcançando os vários setores da produção à medida que se viabilizam instrumentos de controle e mitigação na lógica do mercado. Dessa maneira, restritas à produção capitalista da natureza, as políticas ambientais - que têm como fundamento um entendimento tecnicista e economicista dos conflitos socioambientais - facilitam a apropriação da natureza como um ativo importante para reequilibrar o funcionamento contraditório do capitalismo e, nesse sentido, não são capazes de deter a degradação ambiental que ameaça a sobrevivência da humanidade, mas não é obstáculo para a reprodução do capital.

\section{Referências}

ALVES, K. L. Situação geral das UCs no Brasil. In: RAMOS, A.; CAPOBIANCO, J. P. (Org.).

Unidades de conservação no Brasil: aspectos gerais, experiências inovadoras e a nova legislação (Snuc). São Paulo: ISA, 1996. p. 9-20.

ARENDT, H. Origens do totalitarismo. São Paulo: Companhia das Letras, 1989.

BARRETO FILHO, H. T. Notas para uma história social das áreas de proteção integral no Brasil. In: RICARDO, F. (Org.). Terras indígenas e unidades de conservação da natureza: o desafio das sobreposições. São Paulo: ISA, 2004. p. 53-63.

BIM, J. B. O. Mosaico do Jacupiranga - Vale do Ribeira, São Paulo: conservação, conflitos e soluções socioambientais. Dissertação (Mestrado em Geografia Física) Faculdade de Filosofia, Letras e Ciências Humanas, Universidade de São Paulo, São Paulo, 2012.

CHESNAIS, F; SERFATI, C. "Ecologia" e condições físicas de reprodução social: alguns fios condutores marxistas. Crítica Marxista, São Paulo, v.1, n.16, p. 39-75, 2003.

DIEGUES, A. C. O mito moderno da natureza intocada. 6a ed. São Paulo: Hucitec/ USP, 2008.

DIEGUES, A. C.; VIANNA, L. P. Conflitos entre populações humanas e unidades de conservação e Mata Atlântica. São Paulo: Nupaub, 1995.

HARVEY, D. O novo imperialismo. São Paulo: Loyola, 2004.

ICMBio. INSTITUTO CHICO MENDES DE CONSERVAÇÃO DA BIODIVERSIDADE. Unidades de conservação. Disponível em: http://www.icmbio.gov.br/portal/unidades-de-conservacao. Acesso em: 10 jul. 2019.

KATZ, C. Whose nature, whose culture? Private productions of space and the preservation of nature. In: BRAUN, B.; CASTREE, N. (Ed.). Remaking reality: nature at the millennium. London: Taylor \& Francis, 2005.

LIMA, N. Conservação no cerrado, território, política pública: mosaico sertão Veredas-Peruaçu. Tese (Doutorado em Geografia Humana) - Faculdade de Filosofia, Letras e Ciências Humanas, Universidade de São Paulo, São Paulo, 2008. 
MARX, K. Introdução à crítica da economia política. In: MARX, K. Manuscritos econômico-filosóficos e outros textos escolhidos. São Paulo: Abril Cultural, 1985. (Coleção os Pensadores.)

MORAES, A. C. R. Capitalismo, geografia e meio ambiente. Tese (Livre Docência em Geografia Humana) - Faculdade de Filosofia, Letras e Ciências Humanas, Universidade de São Paulo, São Paulo, 2000.

PINHEIRO, M. R. (Org.). Recomendações ao reconhecimento e implantação dos mosaicos de áreas protegidas. São Paulo: GTZ/CI-BR, 2010.

RIBEIRO, W. C. Geografia política e gestão internacional dos recursos naturais. Estudos Avançados, São Paulo, v. 24, n. 68, p. 69-80, 2010.

SANTILLI, J. Socioambientalismo e novos direitos: proteção jurídica à diversidade biológica e cultural. São Paulo/Petrópolis: ISA/Instituto Internacional de Educação do Brasil, 2005.

SILVA-SÁNCHEZ, S. S. Cidadania ambiental: novos direitos no Brasil. São Paulo: Annablume, 2010.

SIMÕES, E. O dilema das decisões sobre populações humanas em parques: jogo compartido entre técnicos e residentes no Núcleo Picinguaba. Tese (Doutorado do Programa Ambiente \& Sociedade) - Instituto de Filosofia e Ciências Humanas, Universidade Estadual de Campinas, Campinas, 2010.

SMITH, N. Nature as accumulation strategy. In: PANITCH, L.; LAYS, C. (Ed.). Socialist Register 2007: Coming to Terms with Nature. New York/London/Halifax: 2007. p. 16-36. v. 43.

SMITH, N. Desenvolvimento desigual: natureza, capital e produção do espaço. Rio de Janeiro: Bertrand Brasil, 1988. 